\title{
INHALT / SOMMAIRE
}

Vorwort / Avant-propos

Philippe DEPREUX

Introduction

Bruno POTTIER

Les circoncellions: formation d'une élite rurale monastique autonome dans l'Afrique du Nord des $I V^{e}$ et $V^{\mathfrak{e}}$ siècles

François MARTIN

La rébellion de Sun En et Lu Hsün (396-412)

Jean-Claude CHEYNET

Se révolter légitimement contre le basileus?

\section{Steffen PATZOLD}

Ipsorum necesse est sub hanc dissensionem animas periclitari

Les révoltes dans la vie monastique médiévale en Europe occidentale ....

Philippe DEPREUX

Défense d'un statut et contestation d'un modèle de société. Conjuration, révolte et répression dans l'Occident du Haut Moyen Âge

\section{Alain SAINT-DENIS}

Instigateurs et acteurs des premières communes françaises

(fin $\mathrm{XI}^{\mathrm{e}}$-premier tiers du XII $\mathrm{r}^{\mathrm{e}}$ siècle)

Claudia ZEY

Autour des soulèvements communaux en Italie septentrionale et centrale aux $\mathrm{XI}^{\mathrm{e}}$ et $\mathrm{XII}^{\mathrm{e}}$ siècles

Uwe ISRAEL

Von Cola di Rienzo zu Stefano Porcari. Revolten im Rom des 14. und

15. Jahrhunderts

Jörg PELTZER

Révoltes en Angleterre au Moyen Âge central et tardif 


\section{Kai-Henrik GÜNTHER}

Gleichheitsvorstellungen als Beweggrund aufständischen Handelns in mitteleuropäischen Städten des Spätmittelalters: Braunschweig, Brügge, Ypern, Zürich

Marianne SÁGHY

Le révolté "hongrois«: conspirations, attentats et conflits nationaux dans le royaume de Hongrie à la fin du Moyen Âge 205

\section{Vincent CHALLET}

Peuple et élites: stratégies sociales et manipulations politiques dans

les révoltes paysannes (France, $\mathrm{XIV}^{\mathrm{e}}-\mathrm{XV}^{\mathfrak{e}}$ siècle)

Werner TROSSBACH

Tagelöhner und dörfliche Eliten: Überlegungen zum Verhältnis

von Struktur- und Ereignisgeschichte im Bauernkrieg (1524-1526)

Olivia CARPI

Élites citadines et sédition en France à l'époque des troubles

de religion

Hanna VOLLRATH

Zusammenfassung

Personenregister / Index des personnes

Autorinnen und Autoren / Les auteurs 